\title{
Article
}

\section{Melatonin for the management of sleep problems in children with neurodevelopmental disorders: a systematic review and meta-analysis}

Abdelgadir, Ibtihal Siddiq, Gordon, Morris and Akobeng, Anthony K Available at https://clok.uclan.ac.uk/22738/

Abdelgadir, Ibtihal Siddiq, Gordon, Morris orcid iconORCID: 0000-0002-12165158 and Akobeng, Anthony K (2018) Melatonin for the management of sleep problems in children with neurodevelopmental disorders: a systematic review and meta-analysis. Archives of Disease in Childhood. ISSN 0003-9888

It is advisable to refer to the publisher's version if you intend to cite from the work. http://dx.doi.org/10.1136/archdischild-2017-314181

For more information about UCLan's research in this area go to http://www.uclan.ac.uk/researchgroups/ and search for <name of research Group>.

For information about Research generally at UCLan please go to http://www.uclan.ac.uk/research/

All outputs in CLoK are protected by Intellectual Property Rights law, including Copyright law. Copyright, IPR and Moral Rights for the works on this site are retained by the individual authors and/or other copyright owners. Terms and conditions for use of this material are defined in the policies page. 


\section{Melatonin for the management of sleep problems in children with}

neurodevelopmental disorders: a systematic review and meta-analysis

Ibtihal Abdelgadir ${ }^{1}$, MBBS, MD, MRCPCH, FRCPCH, CCT MSc; Morris Gordon ${ }^{2}$, MBChB, MMed, PHD, FRCPCH, FHEA, FACAdmed; Anthony K. Akobeng 1,3, MB ChB, MD, FRCPCH, MRCP, CCST, MPH.

${ }^{1}$ Sidra Medical and Research Center, P O Box 26999, Doha, Qatar, ${ }^{2}$ School of Medicine and Dentistry, University of Central Lancashire, Preston, UK, ${ }^{3}$ Weill Cornell Medical College, Doha, Qatar

Correspondence to: I S Abdelgadir, iabdelgadir@ hotmail.com. Sidra Medical and Research Center,

P O Box 26999, Telephone number +97433444722

Word count $=\underline{3212}$ 


\section{ABSTRACT}

Importance: Children with neurodevelopmental disorders have a higher prevalence of sleep disturbances. Currently there is variation in the melatonin use, hence an up to date systematic review is indicated to summarize the current available evidence.

Objectives: To determine the efficacy and safety of melatonin as therapy for sleep problems in children with neurodevelopmental disorders.

Data sources and study selections: PubMed, Embase, CINAHL, and the Cochrane Central Register of Controlled Trials from inception up to March 2017. Two reviewers performed data assessment and extraction. We assessed randomized controlled trials that compared melatonin with placebo or other intervention for the management of sleep disorders in children $(<18$ years $)$ with neurodevelopmental disorders.

Data extraction and synthesis: We identified $\underline{3262}$ citations, and included $1 \underline{3}$ studies in this metaanalysis.

Main outcomes: Included total sleep time, sleep onset latency, frequency of nocturnal awakenings, and adverse events.

Results: Thirteen RCTs $(\mathrm{n}=\underline{682})$, met the inclusion criteria. A meta-analysis of $\underline{9}$ studies $(\mathrm{n}=\underline{541})$ showed that melatonin significantly improved total sleep time compared with placebo (MD $4 \underline{8.26} \mathrm{~min}$, $95 \%$ CI: $3 \underline{6.78}$ to $\left.\underline{59.73}, \mathrm{I}^{2}=3 \underline{1} \%\right)$. In $1 \underline{1}$ studies $(\mathrm{n}=\underline{581})$, sleep onset latency improved significantly with melatonin use (MD $=-28 . \underline{97}, 95 \% \mathrm{CI}-\underline{39.78}$ to $-1 \underline{8.17})$. No difference was noted in the frequency of nocturnal awakenings $(\mathrm{MD}=-0.49,95 \% \mathrm{CI}-1.71$ to 0.73$)$. No medication-related serious adverse event was reported.

Conclusion: Melatonin appeared safe and effective for improving sleep in the studied children. The overall quality of the evidence is limited due to heterogeneity and inconsistency. Further research is needed.

Keywords: Melatonin, Developmental Disorders, Sleep disorders, Systematic Reviews, Meta-analysis, Randomized controlled trials. 


\section{What is already known on this subject}

- Children with neurodevelopmental disorders have a higher prevalence of sleep disturbances.

- Previous studies suggested that melatonin might be beneficial for improving sleep disorders in these children.

\section{What this study adds}

- Evidence from this comprehensive systematic review and meta-analysis shows that melatonin may be effective for improving total sleep time and sleep latency in children with neurodevelopmental disorders.

- No serious adverse events were associated with the use of melatonin in these children.

- The overall quality of the evidence is limited due to heterogeneity and inconsistency.

- Further well designed, larger randomised controlled trials are needed to further conclude on these findings 


\section{INTRODUCTION}

Children with neurodevelopmental disorders have a higher prevalence of sleep disturbances than their unaffected peers and this could potentially have a negative effect on learning and behaviour.[1] Recent studies suggest that the prevalence of sleep disorders in children with developmental disabilities ranges from $25 \%$ to $86 \%$.[2] Melatonin is a neurohormone, well known for its effect on the regulation of the circadian sleep-wake rhythm. In physiologic conditions, it has a plasma concentration that follows a circadian rhythm, with low levels during the day and high levels at night. In humans, the peak secretion typically occurs at around 2 am, which explains the name "darkness hormone".[3] Melatonin appears to have other multiple actions other than sleep regulation. It has potent antioxidant action,[4] protects the organism from carcinogenesis and has an immune modulation effect.[5] Studies of melatonin production in children with sleep disorders were often limited by small sample sizes and were not entirely consistent, but reported abnormalities in melatonin production strongly indicate that nocturnal secretion of melatonin is often low in children with neurodisability and those with autistic spectrum disorders.[6]

It has been suggested from previous studies that melatonin might be effective on improving total sleep time, $[7,8]$ time to sleep onset "sleep latency", $[8,9,10]$ and number of awakenings.[7]

Many children with developmental disorders, such as autistic spectrum disorder, attentiondeficit/hyperactivity disorder and intellectual disability, experience sleep disturbances and may potentially benefit from melatonin treatment.[11] In five studies assessed by Hollway et al, information was given on parental perception of the effect of melatonin on their family life.[2] Parents and caregivers reported that they spent less time and effort in getting their child to stay in bed, while daytime behaviour and alertness on the part of the child also improved.

The results of a systematic review conducted by Appleton et al in 2004 suggested that melatonin might be effective in reducing sleep latency in children with neurodevelopmental disabilities.[10] Since that review, there have been a number of clinical trials that have investigated the effect of melatonin on the sleep pattern in children with neurodevelopmental disorders. Currently in the UK, there is variation in the guidance on the use of melatonin between clinical commissioning groups. An up to date systematic review using the Cochrane Collaboration format is indicated to summarise the current evidence on the use of melatonin compared with placebo for the treatment of sleep disorders in children with neurodevelopmental disorders. This review evaluated the effect of melatonin on total sleep time, sleep 
onset latency, frequency of nocturnal awakening, early-morning awakening time, parental perception of the effect of melatonin treatment on their child's behaviour, and adverse events.

\section{MATERIAL AND METHODS}

\section{Study selection and search strategy}

This systematic review was conducted according to the Preferred Reporting Items for Systematic Reviews and meta-analysis (PRISMA) criteria. A study protocol was conducted and is available online under this registration number: PROSPERO CRD42015024170.

We searched the following databases from inception to March 2017, that was then updated January 2018: PubMed, Embase, CINAHL and the Cochrane Central Register of Controlled Trials (CENTRAL). Reference lists from retrieved articles were inspected to identify additional citations that may have been missed by the electronic searches. We also searched for current unpublished ongoing clinical trials on the following websites: www.clinicaltrials.gov and www.controlled-trials.com. The search strategy included these terms: Melatonin (All Fields) AND (Neurodevelopmental disorder* OR Neurodevelopmental disabilit* OR Developmental delay* OR Behaviour disorder* OR Attention deficit hyperactivity disorder OR ADHD OR Autistic spectrum disorder or autism or Asperger syndrome OR Communication disorder* OR Sleep OR Sleep disorder* OR Insomnia OR Sleep quality OR Sleep difficult*OR Sleep disturbance* OR Sleep problem*) (see Appendix 1).

We applied no language restriction, and English translation was to be considered for relevant studies when needed.

\section{Study characteristics}

We included randomized controlled trials (RCTs) that compared melatonin to either placebo or any other intervention. The unit of analysis was the participating child that needed melatonin for sleep disorder. Cluster randomized trials were not included.

Participants were patients below_18 years of age with neurodevelopmental and sleep disorders. Interventions of the included trials included the therapeutic use of melatonin for sleep disorder. Melatonin should have been compared with placebo or any other intervention.

The primary outcome measure was total sleep time. Secondary outcome measures included: sleep onset latency, frequency of nocturnal awakening and early-morning awakening time, parental perception of 
the effect of melatonin treatment on their child's behaviour, quality of life for both children and families and adverse events.

\section{Data extraction and quality assessment}

Using the above search strategy, papers that appeared to be potentially relevant were identified by two reviewers (IA, MG). We obtained full-text versions of all studies that were included in the review for assessment. We used a data extraction form that included risk of bias assessment, demographic information, methodology, intervention details, and reported outcomes. Two reviewers (IA, MG) extracted the data independently from each eligible study and compared the extracted data for any differences, which was resolved by discussion. Any disagreement was discussed and where necessary resolved by consultation with the third author (AA). We used the Cochrane Collaboration's Review Manager (RevMan, version 5.3) for data processing and analysis.

The criteria outlined in the Cochrane Handbook for Systematic Reviews of Interventions were used to assess the risk of bias.[12] Two reviewers (IA, MG) independently assessed the risk of bias for each study. Any disagreement was resolved by discussion or by involving a third reviewer (AA). We assessed the risk of bias according to the following criteria: random sequence generation, allocation concealment, blinding of participants and personnel, blinding of outcome assessment, incomplete outcome data, selective outcome reporting and other bias.[12] We graded each potential risk of bias as being at low, high or unclear risk. We contacted the authors of published studies for further clarification or to provide additional information when required.

\section{Statistical analysis}

We used the Cochrane Collaboration's Review Manager (RevMan) software (version 5.3) for statistical analysis. We performed meta-analysis for the outcomes that were amenable for pooled data synthesis using the random-effects model. We calculated the mean difference (MD) and corresponding $95 \%$ confidence intervals (CIs) for continuous outcomes measured using the same units. Narrative description was used to synthesize trial outcome data where data cannot be combined or significant heterogeneity exists

\section{Assessment of Subgroups and Statistical Heterogeneity}

Heterogeneity was assessed by the visual inspection of the forest plots and was tested using the $\mathrm{I}^{2}$ statistic, in which I $\mathrm{I}^{2}>50 \%$ indicated significant heterogeneity.[13] Planned subgroup analyses were based on: a) type of neurodevelopmental disability, b) dosage of 
melatonin, c) duration of treatment, d) age and e) the method used for sleep times measurements. We used sensitivity analyses to explore the impact of including only non-crossover studies in the analysis. All analyses were also subjected to fixed-effects model analysis to explore differences that would indicate heterogeneity. We used the GRADE system [14] to assess the quality of the body of evidence associated with specific outcomes (total sleep time, sleep onset latency, frequency of nocturnal awakening, early-morning awakening time). A funnel plot was to be used to investigate the potential of reporting and publication biases when at least 10 studies contributed to an outcome.

\section{RESULTS}

\section{Identifying studies and quality assessment}

We identified 3262 citations from the database searches of the pre-specified websites. Seven more citations were identified from searching other resources. $\underline{3217}$ studies were excluded from screening of titles and abstracts. We screened full paper copies of $5 \underline{2}$ citations that were potentially eligible for inclusion in the review. From the full texts, seventeen studies were excluded as duplicates, fifteen studies were excluded as non-RCTs, three studies included adults' data, two studies were excluded because melatonin was not used for sleep disorder and two studies assessed children with no neurodevelopmental disorders. We included $1 \underline{3}$ studies [15-26] involving a total of $\underline{682}$ children in this systematic review. A flow chart detailing the studies' selection process is shown in Figure 1.

\section{Characteristics of eligible studies}

All the included studies were prospective RCTs (see Table 1). Participants were children below18 years of age that had both neurodevelopmental and sleep disorders. The studies were conducted in Europe, North America and Iran. Eight studies were crossover RCTs.[17, 18, 20, 22, 24-27] The enrolled children were described in the primary studies to have the following neurodevelopmental disabilities: neurodevelopmental disorder,[15, 17, 24] autistic spectrum disorders,[16, 18, 19, 27] attention-deficit hyperactivity disorder (ADHD),[21, 23, 25] Fragile X Syndrome,[26] Rett syndrome [20] and mental retardation.[22] Sleep data was recorded either by using sleep diaries ( $\underline{7}$ studies),[ 17, $18, \underline{19}, 2 \underline{1}, 2 \underline{2}, 25,27]$ using actigraph (4 studies),[19, 20, 23, 24, 26] or both (2 studies).[15, 16] The melatonin used was fast release melatonin in 10 studies, [15, 17, 18, 20-2 $\underline{3}, 2 \underline{5}-2 \underline{7}]$ and two studies used a combination of the slow and fast melatonin preparations.[16, 24] ${ }^{\cdot}$ One further study used slow release melatonin [19]. The dosages used ranged from 0.1 -12 mg. Escalating dose of melatonin according to 
response was used in three of the included studies.[15, 19,27] Duration of melatonin treatment ranged from one to $\underline{13} \underline{\text { weeks. }}$.

\begin{tabular}{|c|c|c|c|c|c|c|}
\hline Study ID & $\begin{array}{l}\text { Countr } \\
\text { y of the } \\
\text { study }\end{array}$ & $\begin{array}{l}\text { Type of } \\
\text { participants' } \\
\text { disorder }\end{array}$ & $\begin{array}{l}\text { Numbe } \\
\text { r of } \\
\text { Childr } \\
\text { en (n) }\end{array}$ & Age group & $\begin{array}{l}\text { Type of } \\
\text { melatonin and } \\
\text { doses }\end{array}$ & $\begin{array}{l}\text { Sleep } \\
\text { diary or } \\
\text { actigraph } \\
\text { record }\end{array}$ \\
\hline $\begin{array}{l}\text { Appleton } \\
\text { 2012.5 }\end{array}$ & UK & $\begin{array}{l}\text { Neurodevelopment } \\
\text { al disorder }\end{array}$ & $\mathrm{n}=110$ & $\begin{array}{l}3-15 \text { years } \\
\text { and } 8 \\
\text { months }\end{array}$ & $\begin{array}{l}0.5-12 \mathrm{mg} \text { slow } \\
\text { release }\end{array}$ & $\begin{array}{l}\text { Both diary } \\
\text { and } \\
\text { Actigraph }\end{array}$ \\
\hline $\begin{array}{l}\text { Cortesi } \\
2012.16\end{array}$ & Italy & $\begin{array}{l}\text { Autism spectrum } \\
\text { disorders }\end{array}$ & $\mathrm{n}=134$ & $4-10$ years & $\begin{array}{l}1 \text {-mg fast- } \\
\text { release and 2- } \\
\text { mg controlled- } \\
\text { release }\end{array}$ & $\begin{array}{l}\text { Both diary } \\
\text { and } \\
\text { Actigraph }\end{array}$ \\
\hline $\begin{array}{l}\text { Dodge } \\
2001.17\end{array}$ & USA & $\begin{array}{l}\text { Moderate to severe } \\
\text { developmental } \\
\text { disability }\end{array}$ & $\mathrm{n}=20$ & $1-12$ years & $\begin{array}{l}5 \mathrm{mg} \text { fast } \\
\text { release } \\
\text { melatonin }\end{array}$ & $\begin{array}{l}\text { Sleep } \\
\text { diary }\end{array}$ \\
\hline $\begin{array}{l}\text { Garstang } \\
2006.18\end{array}$ & UK & $\begin{array}{l}\text { Autistic spectrum } \\
\text { disorder }\end{array}$ & $\mathrm{n}=11$ & 4-16 years & $\begin{array}{l}5 \mathrm{mg} \text { fast } \\
\text { release } \\
\text { melatonin }\end{array}$ & $\begin{array}{l}\text { Sleep } \\
\text { diary }\end{array}$ \\
\hline$\frac{\text { Gringras }}{2017.19}$ & $\begin{array}{l}\text { USA \& } \\
\text { Europe }\end{array}$ & $\begin{array}{l}\text { Autistic spectrum } \\
\underline{\text { disorder }}\end{array}$ & $\mathrm{n}=125$ & 2-17.5 years & $\begin{array}{l}\frac{2-5 \mathrm{mg} \text { slow }}{\text { release }} \\
\underline{\text { melatonin }}\end{array}$ & $\begin{array}{l}\text { Sleep } \\
\text { diary }\end{array}$ \\
\hline $\begin{array}{l}\text { McArthur } \\
\text { 1998. } \underline{20}\end{array}$ & USA & $\begin{array}{l}\text { Girls with Rett } \\
\text { syndrome }\end{array}$ & $\mathrm{n}=9$ & 4-17 years & $\begin{array}{l}2.5-7.5 \mathrm{mg} \\
\text { fast release } \\
\text { melatonin }\end{array}$ & Actigraph \\
\hline $\begin{array}{l}\text { Mostafavi } \\
2012 .^{21}\end{array}$ & Iran & $\begin{array}{l}\text { Attention-deficit } \\
\text { hyperactivity } \\
\text { disorder (ADHD). }\end{array}$ & $\mathrm{n}=50$ & $7-12$ years & $\begin{array}{l}3 \text { or } 6 \mathrm{mg} \text { fast } \\
\text { release } \\
\text { melatonin }\end{array}$ & $\begin{array}{l}\text { Sleep } \\
\text { diary }\end{array}$ \\
\hline $\begin{array}{l}\text { Niederhofer } \\
\text { 2003. }{ }^{\mathbf{2}}\end{array}$ & Austria & Mental retardation & $\mathrm{n}=20$ & 14-18 Years & $\begin{array}{l}0.1-0.3 \mathrm{mg} \text { fast } \\
\text { release } \\
\text { melatonin }\end{array}$ & $\begin{array}{l}\text { Sleep } \\
\text { diary }\end{array}$ \\
\hline $\begin{array}{l}\text { Van der } \\
\text { Heijden } \\
2007 . \underline{2}\end{array}$ & $\begin{array}{l}\text { Netherl } \\
\text { and }\end{array}$ & $\begin{array}{l}\text { Attention-deficit } \\
\text { hyperactivity } \\
\text { disorder (ADHD). }\end{array}$ & $\mathrm{n}=105$ & $6-12$ years & $\begin{array}{l}3 \text { or } 6 \mathrm{mg} \text { fast } \\
\text { release } \\
\text { melatonin }\end{array}$ & Actigraph \\
\hline $\begin{array}{l}\text { Wasdell } \\
2008 . \mathbf{2 4}\end{array}$ & Canada & $\begin{array}{l}\text { Neurodevelopment } \\
\text { al disabilities }\end{array}$ & $\mathrm{n}=50$ & $2-18$ years & $\begin{array}{l}1 \mathrm{mg} \text { fast, } 4 \mathrm{mg} \\
\text { sustained } \\
\text { release } \\
\text { melatonin }\end{array}$ & Actigraph \\
\hline $\begin{array}{l}\text { Weiss } \\
2006 . \underline{2} \underline{ }\end{array}$ & Canada & $\begin{array}{l}\text { Adolescents With } \\
\text { ADHD }\end{array}$ & $\mathrm{n}=19$ & $6-14$ years & $\begin{array}{l}5 \mathrm{mg} \text { fast } \\
\text { release } \\
\text { melatonin }\end{array}$ & $\begin{array}{l}\text { Sleep } \\
\text { diary }\end{array}$ \\
\hline $\begin{array}{l}\text { Wirojanan } \\
\text { 2009.므 }\end{array}$ & Canada & $\begin{array}{l}\text { Autism, Fragile X } \\
\text { Syndrome, or } \\
\text { Autism and Fragile } \\
\text { X Syndrome }\end{array}$ & $\mathrm{n}=12$ & $2-15.3$ years & $\begin{array}{l}3 \mathrm{mg} \text { fast } \\
\text { release } \\
\text { melatonin }\end{array}$ & Actigraph \\
\hline
\end{tabular}




\begin{tabular}{|l|l|l|l|l|l|l|}
\hline $\begin{array}{l}\text { Wright } \\
\text { 2011.27 }\end{array}$ & UK & $\begin{array}{l}\text { Autism Spectrum } \\
\text { Conditions }\end{array}$ & $\mathrm{n}=17$ & $4-16$ years & $\begin{array}{l}2-10 \text { fast } \\
\text { release } \\
\text { melatonin }\end{array}$ & $\begin{array}{l}\text { Sleep } \\
\text { diary }\end{array}$ \\
\hline
\end{tabular}

Table 1. Characteristics of included studies

\section{Risk of bias}

The risk of bias assessment across all $1 \underline{3}$ included studies is shown in Figure 2 and Figure 3. Eight studies gave sufficient details about randomization and allocation to be assessed as having a low risk of

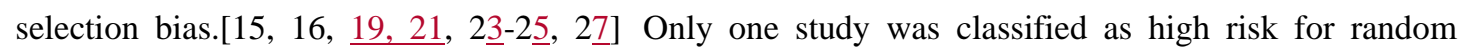
sequence generation.[26] Eleven studies were classified as low risk for participants and personnel blinding.[15-17, 20-27] Six studies adopted good measures to reduce the risk of bias in outcome

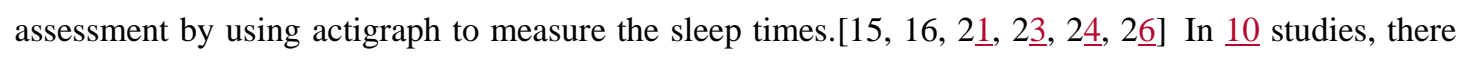
were enough outcomes assessments data to be classified as low risk,[16, 19-27] and all the $1 \underline{3}$ studies included in the review were of low risk for reporting bias.

\section{Effect of melatonin}

\section{Total sleep time}

Nine studies $(\mathrm{n}=\underline{5} 41)$ provided sufficient data for this outcome and these were included in the data synthesis.[15-1모 $2 \underline{3}, 2 \underline{4}, 2 \underline{6}, 2 \underline{7} \perp$ There was a statistically significant higher total sleep time in the melatonin group compared with the placebo group ( $\mathrm{MD}=4 \underline{8.26}$ minutes, $95 \%$ CI $3 \underline{6.79}$ to $\underline{59.73}$ ) (Figure 4). There was mild heterogeneity among the studies $\left(I^{2}=31 \%\right)$. A sensitivity analysis using the fixed effects model made no significant difference to the results. Analysing only the non-crossover RCTs also made no significant difference to the results: melatonin remained superior in improving total sleep time (MD $=\underline{51.26}, 95 \%$ CI $\underline{42.56}$ to 59.96$)$.

\section{Sleep onset latency}

Sleep onset latency was defined as the time taken to fall asleep by most of the studies' authors. All the $1 \underline{3}$ included studies assessed this outcome, however we included only $1 \underline{1}$ studies $(\mathrm{n}=\underline{581})$ that provided sufficient data in a suitable format to be included in the data synthesis.[15-20, 23-2] The pooled data synthesis showed that sleep onset latency is significantly improved by the use of melatonin $(\mathrm{MD}=-$ 28.97, 95\% CI $-\underline{39.78}$ to $-\underline{18.17}$ ) (Figure 5). There was severe heterogeneity among the included 
individual studies $\left(\mathrm{I}^{2}=8 \underline{2} \%\right)$ (Figure 5). A funnel plot for this outcome showed asymmetry of the studies' distribution. This would indicate under reporting of smaller studies (Figure 6).

\section{Frequency of nocturnal awakening}

The frequency of the times that participants got awake after starting sleep was measured and data were suitable for meta-analysis in 6 studies $(\mathrm{n}=277) .[16-18,2 \underline{4}, 2 \underline{5}, 2 \underline{]}]$

The results showed that there was no significant difference between participants receiving melatonin or placebo $(\mathrm{MD}=-0.49,95 \% \mathrm{CI}-1.71$ to 0.73$)$. There was severe heterogeneity among the included individual studies $\left(I^{2}=95 \%\right)$ (Figure 7).

\section{Adverse events}

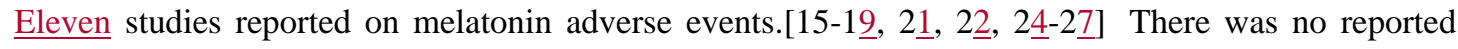
difference from the primary studies between melatonin and placebo groups, but there was not suitable data to allow meta-analysis on this outcome.

\section{Child's behaviour}

The parental perception of the effect of melatonin treatment on their child's behaviour for both children

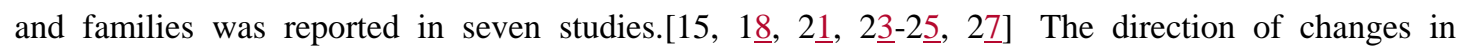
children's behaviour favoured melatonin in four of these studies, $[15,18,24,27]$ and parents felt their children behaviour improved with melatonin treatment compared with placebo. However, studies that assessed children with ADHD reported no differences in behaviour between children received melatonin and those who received placebo treatment.[2스, 2ㄹ, 25]

\section{Other outcomes}

There wasn't enough data to allow a report on early-morning awakening time.

\section{Subgroup analysis}

\section{Outcome: total sleep time}

Subgroup analysis was done for the outcome total sleep time based on the type of neurodevelopmental disorders. Only studies that assessed children with neurodisabilities, [15, 17, 24] and autistic spectrum disorders[16, 18, 19, 27] could be grouped for data synthesis, and the pooled estimate showed a significantly higher total sleep time in the participants who received melatonin compared with placebo, in both neurodisabilities group $(\mathrm{MD}=27.91,95 \% \mathrm{CI} 4.23$ to 51.60$)$ and autistic spectrum disorder 
group $(\mathrm{MD}=\underline{61.30}, 95 \%$ CI $\underline{50.48}$ to $\underline{72.13})$ (Figure 8).

\section{Outcome: Sleep onset latency}

There was heterogeneity among the included studies noted on the initial analysis. This was improved when subgroup analysis was done according to neurodevelopmental disabilities diagnoses that is stated by the primary studies $(\mathrm{MD}=-2 \underline{6.09}, 95 \% \mathrm{CI}-\underline{32.13}$ to -20.05$)\left(\mathrm{I}^{2}=\underline{0} \%\right)$ (Figure 9$)$.

Subgroup analyses on the dosage of melatonin, duration of treatment, and age were not feasible as there was no suitable available data.

\section{GRADE Assessment}

The GRADE quality of evidence for the outcomes: total sleep times, sleep onset latency and frequency of nocturnal awakening were downgraded to moderate because of inconsistency and heterogeneity of the studies.

\section{DISCUSSION}

\section{Summary of the findings}

The results of this systematic review and meta-analysis show that melatonin significantly improves total sleep time by about $4 \underline{8}$ minutes when used for children with neurodevelopmental disabilities. Children with autistic spectrum disorder showed an improvement in their sleep times by a mean of 61 minutes more sleep with melatonin treatment. Sleep onset latency was improved by a mean of about $2 \underline{9}$ minutes. The frequency of night-time awakening was not different between patients who received melatonin and those who received placebo. There was heterogeneity between the studies so it is difficult to conclude on these results. Getting to sleep earlier by around 30 minutes and having an extra $4 \underline{8}$ minutes of sleep might be statistically significant but its clinical significance needs to be evaluated further. Parents and caregivers reported that melatonin improved the rating on health issues and improved sleep and family stress.[29]

The doses of melatonin used varied between the primary studies and no consistency was noted. The dosages used ranged from $0.1-12 \mathrm{mg}$. Escalating dose of melatonin according to response was used in two of the included studies.[15, 19,27] Duration of treatment ranged from 1 week to $\underline{13} \underline{\text { weeks }}$ with no consistent pattern noted among the studies. Both subjective (sleep diary), and objective (Actigraph) measures of sleep were used for assessment of sleep among the primary studies. With sleep diary, 
periods could be missed when a child is awake and not disturbing the family.[15] Actigraphy might pick up restless sleep and artefact movements as being awake.[15] However actigraphy has become an important assessment tool in sleep research and is considered a sensitive and objective tool of assessment in clinical efficacy of interventions in sleep medicine.[30]

Most of the included studies on this meta-analysis (eight out of thirteen) were crossover RCTs. The washout periods between melatonin and placebo treatment groups varied between studies. Only one study had no washout period,[27] and the remainder of the crossover studies had 3-7 days as a washout period. Some authors believed that there could be a carry on effect of melatonin on sleep parameters and circadian rhythm.[15, 29, 31] A recent systematic review on the pharmacokinetics of melatonin showed that the maximum concentration of melatonin after supplementation would be reached after approximately 50 min with oral immediate-release formulations.[31] The elimination half-life of both oral and intravenous melatonin was about 45 min. Kunz et al, in a study involving 14 adults, showed that exogenous melatonin appeared to normalize circadian variation in human physiology.[32] This effect outlasted the period of melatonin administration and diminished only slowly over time. Even if this carry-over observation might have influenced the results, it is unlikely to have affected the validity of the conclusion of the meta-analysis.[29]

The results of this systematic review are similar to previous systematic reviews with comparable improvements in sleep times and sleep latency when melatonin was used for children with various

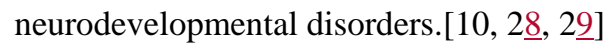

There are some potential limitations of the current study. Some of the included studies had modest sample sizes. This could represent difficulties in recruitment of patients. There were some differences in the detailed study designs such as the different doses of melatonin used by the primary studies. This heterogeneity could have had an impact on the overall results.

\section{Implications for Policy and Practice}

There are variations in current practice and guidelines on the use of melatonin as an adjunct therapy to enhance sleep in children with neurodevelopmental disabilities. The evidence from this study on the use of melatonin in this group of children would help guide current practice and recommendations for future research. Furthermore, no significant adverse events of melatonin were reported by the primary $\underline{\text { studies. }}$ 


\section{Implications for Research}

Using the GRADE criteria the overall quality of the evidence was judged to be moderate. Therefore the strength of our conclusions is limited. Higher quality, adequately powered parallel RCTs investigating the efficacy and safety of melatonin for improving sleep disorders in children with neurodevelopmental disorders is warranted.

\section{CONCLUSIONS}

In conclusion, the results of this study suggest that melatonin improves total sleep time and sleep onset latency with less disturbed night sleep in children with neurodevelopmental disorders. This conclusion is limited by heterogeneity and small sample sizes in the primary studies. 


\section{FOOTNOTES}

Competing interests: All authors have completed the ICMJE uniform disclosure form at www.icmje.org/coi_disclosure.pdf and declare: no support from any organisation for the submitted work; no financial relationships with any organisations that might have an interest in the submitted work in the previous three years; no other relationships or activities that could appear to have influenced the submitted work.

Contribution: IA, AA conceived the systematic review aims and design. IA, MG contributed to the systematic review data assessment, extraction. IA performed data analysis and drafted the manuscript. IA, MG, AA performed interpretation of the results, review of the manuscript and approval of submitted version of the review.

\section{Funding: None.}

Data sharing statement: Data extraction form and protocol available by request to ibtihalsa@hotmail.com 


\section{REFERENCES:}

1. Piazza C, Fisher W, Kahng S. Sleep patterns in children and young adults with mental retardation and severe behavior disorders. Dev Med Child Neurol. 1996; 38 (4):335-344.

2. Hollway, J.A., Aman, M.G. Pharmacological treatment of sleep disturbance in developmental disabilities. A review of the literature. Res Dev Disabil. 2011; 32 (3):939-62.

3. Tordjman S, Najjar I, Bellissant E, et al. Advances in the Research of Melatonin in Autism Spectrum Disorders. Literature Review and New Perspectives. Int. J. Mol. Sci. 2013;14(10):20508-20542.

4. Leon J, Acuña-Castroviejo D, Sainz RM, et al. Melatonin and mitochondrial function. Life Sci. 2004;75(7):765-90.

5. Srinivasan V, Spence DW, Pandi-Perumal, et al. Therapeutic actions of melatonin in cancer: possible mechanisms. Integr Cancer Ther.2008;7(3):189-203.

6. Kostoglou-Athanassiou I. Therapeutic application of melatonin. Ther Adv Endocrinol Metab. 2013;4(1):13-24.

7. Camfield, P., Gordon, K., Dooley J, et al. Melatonin appears ineffective in children with intellectual deficits and fragmented sleep: six 'N of 1' trials. J Child Neurol. 1996;11:341343.

8. Bendz LM, Scates AC. Melatonin treatment for insomnia in pediatric patients with attentiondeficit/hyperactivity disorder. Ann Pharmacother. 2010;44(1): 185-191.

9. Jan MMS. Melatonin for the treatment of handicapped children with severe sleep disorder. Pediatr Neurol.2000; 23:229-232.

10. Phillips L, Appleton R. Systematic review of melatonin treatment in children with neurodevelopmental disabilities and sleep impairment. Dev Med Child Neurol. 2004;46:771775 .

11. Bruni O, Alonso-Alconada D, Besag F, et al. Current role of melatonin in pediatric neurology: clinical recommendations. Eur J Paediatr Neurol. 2015; 19(2):122-133.

12. Higgins T, Green S (editors). Cochrane Handbook for Systematic Reviews of Interventions Version 5.1.0 [updated March 2011]. The Cochrane Collaboration, 2011. Available from www.cochrane-handbook.org.

13. Higgins JP, Thompson SG, Deeks JJ, et al. Measuring inconsistency in meta-analyses. BMJ. 2003;327(7414):557-560.

14. Guyatt GH, Oxman AD, Kunz R, et al. What is "quality of evidence" and why is it important to clinicians? BMJ. 2008;336:995-998.

15. Appleton RE, Jones AP, Gamble C, et al. The use of MElatonin in children with neurodevelopmental disorders and impaired sleep: a randomized, double-blind, placebocontrolled, parallel study (MENDS). Health Technol Assess. 2012;16: i-239.

16. Cortesi F, Giannotti F, Sebastiani T, et al. Controlled-release melatonin, singly and combined with cognitive behavioural therapy, for persistent insomnia in children with autism spectrum disorders: a randomized placebo-controlled trial. J Sleep Res. 2012 Dec;21(6):700-709. DOI: 10.1111/j.1365-2869.2012.01021.x

17. Dodge NN, Wilson GA. Melatonin for the treatment of sleep disorders in children with developmental disabilities. J Child Neurol. 2001;16:581-584. 
18. Garstang J, Wallis M. Randomized controlled trial of melatonin for children with autistic spectrum disorders and sleep problems. Child Care Health Dev. 2006(5);32:585-589.

19. Gringras P, Nir T, Breddy J, et al. Efficacy and Safety of Pediatric Prolonged-Release Melatonin for Insomnia in Children With Autism Spectrum Disorder. J Am Acad Child Adolesc Psychiatry 2017;56(11):948-957.

18.20. McArthur AJ, Budden SS. Sleep dysfunction in Rett syndrome: a trial of exogenous melatonin treatment. Dev Med Child Neurol. 1998;409(3):186-192.

19.21. Mohammadi MR, Mostafavi SA, Keshavarz SA, et al. Melatonin effects in methylphenidate treated children with attention deficit hyperactivity disorder: a randomized double blind clinical trial. Iran J Psychiatry. 2012; 7(2):87-92

20.22. Niederhofer H, Staffen W, Mair A, et al. Brief report: melatonin facilitates sleep in individuals with mental retardation and insomnia. J Autism Dev Disord. 2003;33(4):469-72.

21.23. Van der Heijden KB, Smits MG, Van Someren, et al. Effect of Melatonin on Sleep, Behavior, and Cognition in ADHD and Chronic Sleep-Onset Insomnia. J Am Acad Child Adolesc Psychiatry. 2007;46(2):233-41.

22.24. Wasdell M, Jan J, Bomben M, et al. A randomized, placebo-controlled trial of controlled release melatonin treatment of delayed sleep phase syndrome and impaired sleep maintenance in children with neurodevelopmental disabilities. Pineal Res. 2008;44(1):57-64.

23.25. Weiss MD, Wasdell MB, Bomben MM, et al. Sleep Hygiene and Melatonin Treatment for Children and Adolescents With ADHD and Initial Insomnia. J Am Acad Child Adolesc Psychiatry. 2006; 45(5): 512-9.

24.26. Wirojanan J, Jacquemont S, Diaz R, et al. The Efficacy of Melatonin for Sleep Problems in Children with Autism, Fragile X Syndrome, or Autism and Fragile X Syndrome. J Clin Sleep Med. 2009;5(2):145-50.

25.27. Wright B, Sims D, Smart S, et al. Melatonin Versus Placebo in Children with Autism Spectrum Conditions and Severe Sleep Problems Not Amenable to Behaviour Management Strategies: A Randomized Controlled Crossover Trial. J Autism Dev Disord. 2011;41(2):17584.

26.28. Rossignol DA, Frye RE. Melatonin in autism spectrum disorders: a systematic review and meta-analysis. Dev Med Child Neurol. 2011;53(9):783-92.

27.29. Braam W, Smits MG, Didden R, et al. Exogenous melatonin for sleep problems in individuals with intellectual disability: a meta-analysis. Dev Med Child Neurol. 2009;51(5):340-9.

28.30. Sadeh A. The role and validity of actigraphy in sleep medicine: an update. Sleep Med Rev 2011;15(4):259-67.

29-31. Harpsøe NG, Andersen LP, Gögenur I, et al. Clinical pharmacokinetics of melatonin: a systematic review. Eur J Clin Pharmacol. 2015;71(8):901-9.

30.32. Kunz D, Mahlberg R, Müller C, et al. Melatonin in patients with reduced REM sleep duration: two randomized controlled trials. J Clin Endocrinol Metab.2004;89(1):128-34. 


\section{LIST OF FIGURES}

I. $\quad$ Figure 1: Study flow (PRISMA) diagram

II. Figure 2: Risk of bias graph

III. Figure 3: Risk of bias summary

IV. Figure 4: Total sleep times

V. Figure 5: Sleep onset latency

VI. Figure 6: Funnel plot of the outcome: Sleep onset latency

VII. Figure 7: Frequency of nocturnal awakening; subgroups: actigraph and sleep diary measurements

VIII. Figure 8: Total sleep time. Subgroups: children with neurodisabilities and autistic spectrum disorders

IX. Figure 9: Sleep onset latency. Subgroups: children with neurodisabilities, ADHD and autistic spectrum disorders 
SUPPLEMENTS

i. APPENDIX 1: Search strategy 